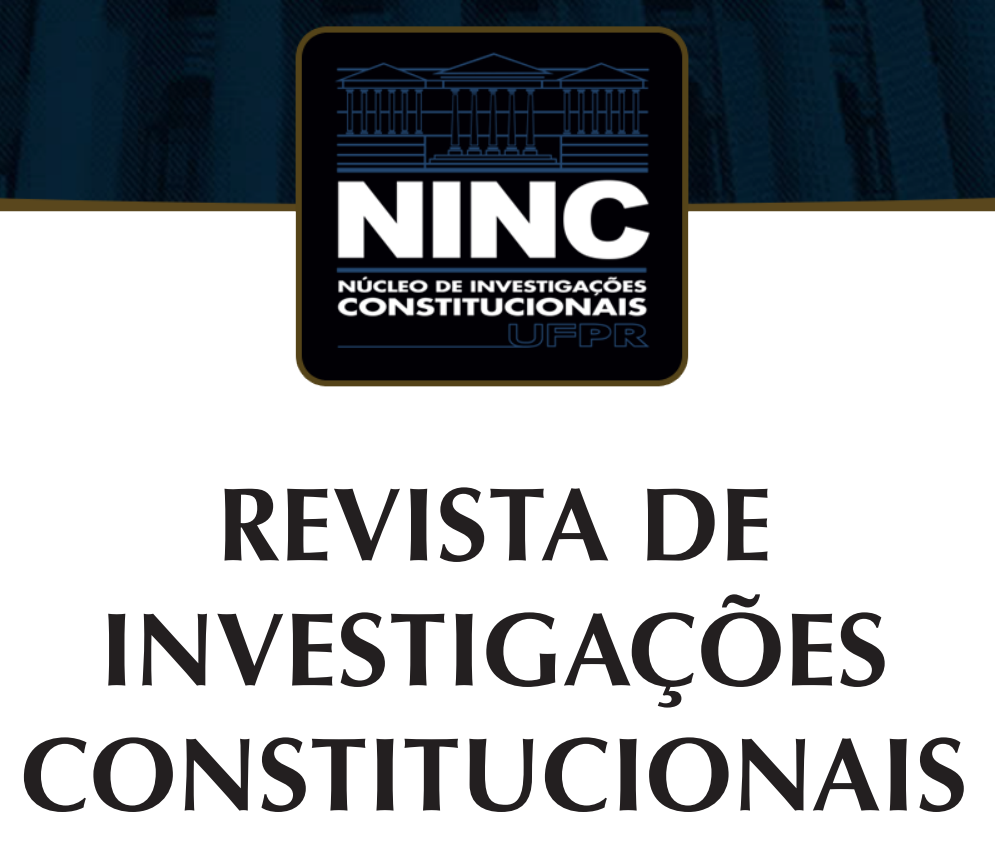

JOURNAL OF CONSTITUTIONAL RESEARCH

vol. 6 | n. 2 | maio/agosto 2019 | ISSN 2359-5639 | Periodicidade quadrimestral Curitiba | Núcleo de Investigações Constitucionais da UFPR | www.ninc.com.br 


\section{La gratuidad de los derechos prestacionales como derechos humanos: una propuesta para su ponderación y otorgamiento}

\section{The gratuity of positive rights as human rights: a proposal for its ponderation and concession}

\section{CARLOS MANUEL ROSALES I,}

'Universidad de Chile (Chile) carmaroga@gmail.com https://orcid.org/0000-0002-2035-9358 Recebido/Received: 18.04 .2018 / April $18^{\text {th }}, 2018$ Aprovado/Approved: 17.11 .2019 / November $17^{\text {th }}, 2019$

\section{Resumen}

El reconocimiento y la implementación de los Derechos Humanos ha generado que su cumplimiento sea en algunos casos a costa del erario. Este artículo analizará s los derechos prestacionales solicitados como Derechos Humanos, deben ser otorgados sin condiciones, o si, al contrario, debe existir un mecanismo para que no haya abuso en su exigibilidad y justiciabilidad.

Palabras clave: derechos humanos; exigibilidad; justiciabilidad; interpretación; ponderación.

\section{Abstract}

The recognition and the implementation of the Human Rights has generated that his fulfillment is in some cases at the cost of the budget. This article will analyze if positive rights requested as human rights, they must be granted without conditions, or if, on the contrary, a mechanism must exist in order that there is no abuse in their enforceability and justiciability.

Keywords: human rights; enforceability; justiciability; interpretation; ponderation.

Como citar esse artigo/How to cite this article: ROSALES, Carlos Manuel. La gratuidad de los derechos prestacionales como derechos humanos: una propuesta para su ponderación y otorgamiento cavalcanti, Revista de Investigações Constitucionais, Curitiba, vol. 6, n. 2, p. 349-373, maio/dez. 2019. DOI: 10.5380/rinc.v6i2.58988.

"Doctor en derecho por la Universidad de Chile (Santiago, Chile). E-mail: carmaroga@gmail.com. 


\section{CONTENIDO}

1. Introducción; 2. Derechos prestacionales; 3. Los derechos humanos; 3.1. reconocimiento; 3.2. tutela y proteccíon; 4. Principios pro personae y progresividad; 5. Exigibilidad y justiciabilidad de los derechos humanos. 6. ¿Cumplimiento incondicional, intrinseco y absoluto?; 7. Casos de estudio; 7.1. Derecho a la salud sin costo al paciente; 7.2. Educación superior gratuita; 7.3. Suministro de agua gratuito; 8 . Conclusiones; 9. Referencias.

\section{INTRODUCCIÓN}

Las leyes son el reflejo de la sociedad. Son la expresión del soberano que cimientan los derechos y garantías. Ellas, sin duda, identifican y permiten dirigir el destino de una nación. para poder alcanzar justicia, bien común, seguridad, etc. ${ }^{1}$ Alimón, para que se pueda acceder a los bienes, derechos y prestaciones que ofrece el Estado, se deben cumplir con los requisitos legales para su operación. ${ }^{2}$

Por otro lado, como es sabido, los Derechos Humanos (DDHH) son una edificación moral universal, que son reconocidos y reconstruidos a partir de diversos tratados, convenciones, declaraciones, entre otros; que sirven como los valores probatorios para medir la legitimidad del Estado. ${ }^{3}$ También, se debe observar que los DDHH son obligatorios e intrínsecos, no requieren de leyes adjetivas para que puedan ser solicitados y cumplimentados. No necesitan una legislación orgánica para su operación, ni consideran la capacidad económica ni la infraestructura del Estado para hacerlos efectivos. ${ }^{4}$

Los derechos fundamentales son triunfos políticos de la sociedad ${ }^{5}$ y los Derechos Humanos provienen de reconocer a la persona con ciertas prerrogativas mínimas, para que pueda vivir dignamente y desarrollar libremente su vida. ${ }^{6}$ Existe un espacio en que ambas esferas confluyen en su identidad y objetivos, más no en la forma de su cumplimiento. Empero, los derechos fundamentales son prestados a la población por medio de una ley que garantiza, derechos, obligaciones, requisitos, operación y

ACKERMAN, Bruce. Social Justice in the Liberal State. New Haven: Yale University Press, 1980. p.164.

2 MARTÍNEZ PORCAYO, José Fernando Ojesto. Poder, derecho y jueces: la jurisdicción como participación política. In: TRIBUNAL ELECTORAL DEL PODER JUDICIAL DE LA FEDERACIÓN (Org.). Testimonios sobre el desempeño del TEPJF. Ciudad de México: Tribunal Electoral del Poder Judicial de la Federación, 2003. p. 469.

3 Vid. SUPREMA CORTE DE JUSTICIA DE LA NACIÓN. Los derechos humanos y su protección por el PJF. Ciudad de México: Suprema Corte de Justicia de la Nación, 2011.

4 He considerado incluir en este análisis la Convención Americana de los Derechos Humanos y el Pacto Internacional de los Derechos civiles y políticos que establecen un conjunto de normas, para que los ciudadanos puedan ejercer plenamente sus derechos políticos, con el objetivo de consolidar y fortalecer el sistema democrático.

5 Ronald Dworkin estima que los principios jurídicos no son patrones extrajurídicos y son vinculantes para el juez. DWORKIN, Ronald. Los derechos en serio. Barcelona: Ariel, 1995. p. 19-22.

6 LARA SÁENZ, Leoncio. Derechos Humanos y Justicia Electoral. Ciudad de México: Tribunal Electoral del Poder Judicial de la Federación, 2003. p. 39-40. 
ejecución de estos. Al contrario de los Derechos Humanos su principal activo es su valor intrínseco, y que sirven como directriz y freno a la actuación de las autoridades. ${ }^{7}$

Por lo que es menester preguntar, ¿los Derechos Humanos tienen más reconocimiento que los derechos fundamentales en un país determinado $?^{8}$ o, dicho de otra manera, si una persona exige el cumplimiento de un $\mathrm{DDHH}$, se debe conceder o consumar sin condiciones previas a diferencia de cualquier ciudadano, que debe apegarse a las normas preestablecidas para obtener acceso a ese bien o servicio.

Este artículo intentará proponer algunos requisitos para la exigibilidad y otorgamiento de algunos DDHH, cuáles serían los mismos y cómo podría considerarse su exigibilidad en un sistema jurisdiccional, sin que se desprotejan los mismos o se demeriten los derechos fundamentales del resto de los ciudadanos. ${ }^{9}$

Se empezará exponiendo que son los derechos prestacionales y luego, diversos teman que provienen de los Derechos Humanos como su reconocimiento, tutela y protección, y si su cumplimiento debe ser absoluto e incondicional. También se expondrán los principios pro personae y de progresividad que amplían la instrumentación de los DDHH. Para materializar lo anterior, se analizarán algunos casos de derechos prestacionales que brinda el Estado (salud, educación, agua y energía eléctrica), los elementos jurídicos para su solicitud, los requerimientos instituciones para que sean efectivos y averiguar cuáles son los límites para ser exequibles.

Esta investigación hace una exposición y disertación, al considerar si un Derecho Humano se debe tutelar y conceder sin condición, o si debe haber requisitos para su exigibilidad y justiciabilidad, para que no se fomente, una política de concesión automática irrestricta y gratuita, fundamentado con base en los $\mathrm{DDHH} .{ }^{10}$

\section{DERECHOS PRESTACIONALES}

El concepto prestaciones incumbe al plural de prestación. Por prestación se reseña a aquel servicio o bien que una autoridad, o en su caso un contratante, que sirven o le piden a otro. ${ }^{11}$

Uno de los términos más divulgados que se genera en relación es con el de prestaciones sociales.

Una prestación es aquel servicio que el Estado o una empresa privada están obligados a brindar por medio de sus empleados y que garantizan bienes o servicios para mejorar la calidad de vida, como es el cuidado de la salud.

7 BIX, Brian. Jurisprudence. Durham: Carolina Academic Press, 2004. p.88.

8 Se tomará en consideración y como referencia algunos casos paradigmáticos, principalmente de México.

9 WILLIAMS, Melissa; WALDRON, Jeremy. Toleration and its limits. New York: New York University Press, 2008. p. 369.

10 Contradicción de Tesis 293/2011.

11 WADE, H. W. Estudio del derecho administrativo. Madrid: Instituto de Estudios Políticos, 1971. p. 18. 
El Estado debe satisfacer las necesidades básicas de la sociedad, en especial, la de las poblaciones en riesgo y que no están en igualdad de circunstancias. El Estado redistribuye la riqueza, y al mismo tiempo presta servicios públicos, cuyos fines son conseguir una vida digna. El desempeño de su función social del Estado debe contar con una infraestructura adecuada de asistencia y destinar recursos suficientes para los programas que lo sostienen y respaldan.

El Estado debe satisfacer las necesidades básicas de la sociedad, en especial, la de las poblaciones en riesgo y que no están en igualdad de circunstancias. El Estado redistribuye la riqueza, y al mismo tiempo presta servicios públicos, cuyos fines son conseguir una vida digna. El desempeño de su función social del Estado debe contar con una infraestructura adecuada de asistencia y destinar recursos suficientes para los programas que lo sostienen y respaldan. ${ }^{12}$

Por regla general, los derechos de prestación son derechos programáticos, debido a que los derechos de prestación exigen un esfuerzo presupuestal y logístico del Estado que sólo se puede realizar con la debida planeación y arbitrio de recursos mediante el procedimiento fijado por la Constitución y las leyes orgánicas. ${ }^{13}$ Gradualmente, los derechos de prestación se les van dando condiciones de eficacia, que hace posible que emane un derecho subjetivo. Por eso, a nivel teórico, en efecto, el estado inicial de un derecho de prestación es su condición programática, que luego tiende a convertirse en un derecho subjetivo. ${ }^{14}$

Los derechos prestacionales, en determinadas situaciones, generan un derecho subjetivo. Esto quiere decir que el titular del derecho puede exigir su ejecución a través de las vías judiciales. En otras ocasiones, los derechos de prestación tienen contenido programático, o sea, su efectividad no puede ser exigida a través de los mecanismos judiciales. En este último caso, en realidad, más que derechos son principios orientadores de la función pública. Los derechos de prestación con contenido programático tienen tal entidad porque precisamente son sólo un programa de acción estatal, una intención institucional. ${ }^{15}$

\footnotetext{
12 NINO, Carlos S. The Constitution of deliberative democracy. New Haven: Yale, 1996. p. 1-5.

13 Randy Barnett estima que la legitimidad de las normas se obtiene por el proceso de elaboración de las mismas; por lo que, cuando los legisladores más se ajusten y respeten al procedimiento legislativo, más legítimas serán las normas producidas. BARNETT, Randy. Restoring the lost constitution. Princeton: Princeton University Press, 2004.

14 Sentencia de la Corte constitucional colombiana T 207/95.

15 COSSío díAZ, José Ramón. Problemas de la Justicia Constitucional. In: OROZCO HENRíQUEZ, J. Jesús (Coord.). Sistemas de Justicia electoral: Evaluación y perspectivas. Ciudad de México: IFE, 1999. p. 397. La relevancia de este principio es fundamental en los denominados derechos sociales. Vid, CARBONELL, Miguel. Corte, jueces y política. Ciudad de México: Fontamara, 2007. p. 23.
} 


\section{LOS DERECHOS HUMANOS}

El contenido de los Derechos Humanos reside en expectativas de actuación por parte de los entes de autoridad, por lo que las personas deben contar con los medios que garanticen la realidad de tales aspiraciones. Para ello, las garantías de protección de los Derechos Humanos son técnicas y medios que permiten lograr la eficacia de estos; en su ausencia, el goce de los derechos que reconoce el orden constitucional no puede materializarse en las personas. ${ }^{16}$

La dignidad humana funge como un principio jurídico que permea en todo el ordenamiento, pero también como un derecho fundamental que debe ser respetado en todo caso, cuya importancia resalta al ser la base y condición para el disfrute de los demás derechos y el desarrollo integral de la personalidad. ${ }^{17}$ Así las cosas, la dignidad humana no es una simple declaración ética, sino que se trata de una norma jurídica que consagra un derecho fundamental a favor de la persona y por el cual se establece el mandato constitucional a todas las autoridades, e incluso particulares, de respetar y proteger la dignidad de todo individuo, entendida ésta -en su núcleo más esencialcomo el interés inherente a toda persona, por el mero hecho de serlo, a ser tratada como tal y no como un objeto, a no ser humillada, degradada, envilecida o cosificada. ${ }^{18}$

Acompañado a la dignidad, es indispensable que se goce del libre desarrollo de la personalidad, ${ }^{19}$ esto significa el reconocimiento del Estado sobre la facultad natural de toda persona a ser individualmente como quiere ser, sin coacción ni controles injustificados, con el fin de cumplir las metas u objetivos que se ha fijado, de acuerdo con sus valores, ideas, expectativas, gustos, etcétera. ${ }^{20}$

Todas las autoridades, en el ámbito de sus competencias, tienen la obligación de promover, respetar, proteger y garantizar los derechos humanos de conformidad con los principios de universalidad, interdependencia, indivisibilidad y progresividad, los que consisten en lo siguiente: i) universalidad: que son inherentes a todos y conciernen a la comunidad internacional en su totalidad; en esta medida, son inviolables, lo que no quiere decir que sean absolutos, sino que son protegidos porque no puede infringirse la dignidad humana, ${ }^{21}$ pues lo razonable es pensar que se adecuan a las circunstancias; por ello, en razón de esta flexibilidad es que son universales, ya que su

\footnotetext{
16 Derechos humanos. Naturaleza del concepto "garantías de protección".

17 CARMONA CUENCA, Encarna. Los derechos sociales de prestación y el derecho a un mínimo vital. Anuario multidisciplinar para la modernización de las administraciones públicas, Sevilla, n. 2, p. 173-197, 2006. p. 185.

18 Dignidad humana. Constituye una norma jurídica que consagra un derecho fundamental a favor de las personas y no una simple declaración ética.

19 Vid, SUPREMA CORTE DE JUSTICIA DE LA NACIÓN. Dignidad humana. Ciudad de México: PJF, 2013.

20 Derecho al libre desarrollo de la personalidad. Aspectos que comprende.

21 ALEXY, Robert. La construcción de los derechos fundamentales. Buenos Aires: Ad hoc, 2010. p. $24 ; 44$.
} 
naturaleza permite que, al amoldarse a las contingencias, siempre estén con la persona. ii) interdependencia e indivisibilidad: que están relacionados entre sí, esto es, no puede hacerse ninguna separación ni pensar que unos son más importantes que otros, deben interpretarse y tomarse en su conjunto y no como elementos aislados. ${ }^{22}$

\subsection{Reconocimiento}

Los Derechos Humanos tienen dos reconocimientos, uno de índole moral, y otro normativo. En el primero, se reconoce a la persona por el simple hecho de ser humano; posee un conjunto de derechos inalienables, indivisibles, imprescriptibles y universales, y que no necesitan estar comprendidos dentro de alguna norma adjetiva o substantiva para su cumplimiento. El otro sistema que se le conoce como positivista, les da su valor a los DDHH a partir de estar incorporados a un cuerpo jurídico nacional. Estos sistemas jurídicos los adaptan y los adoptan a partir de tratados, convenciones, declaraciones, y demás instrumentos internacionales de derechos humanos, que fueron ratificados por ese Estado.

\subsection{Tutela y protección}

Uno de los elementos que perfeccionan a las normas, es que sean tuteladas y protegidas, por la vía de la acción del Estado. ${ }^{23}$ Esto significa, que las normas tendrán efectividad, cuando están plenamente garantizadas a la población, y con ello, se resguarde su efectividad. En el caso de los DDHH, la tutela es una consecuencia de su reconocimiento, lo que provoca que la autoridad tenga que cuidar el ejercicio y la realización de estos. ${ }^{24}$

La tutela sirve como guía o amparo de las personas, al solicitar se respeten sus derechos contra las acciones de agentes públicos o privados. La protección es la defensa que coloca un límite a la acción del Estado, para que no se conculquen los mismos, y en su caso, se investigue las violaciones u omisiones, y se sancionen esas conductas. ${ }^{25}$

Ambas son complementarias, la tutela nos coloca una directriz de actuación y la protección, se realiza en dos sentidos. ${ }^{26}$ En el primero, como función preventiva para que no se atente contra los DDHH, y en un segundo instante, para que en caso de que

\footnotetext{
22 Principios de universalidad, interdependencia, indivisibilidad y progresividad de los derechos humanos.

23 ACKERMAN, Bruce. We the people. Foundations. Cambridge: Harvard University Press, 1991. p. 224.

24 SILVA HENAO, Juan Fernando. Evolución y origen del concepto de 'Estado Social' incorporado en la Constitución Política colombiana de 1991. Ratio Juris, vol. 7, número 14, ene./jun. 2012. p. 141-158.

25 VILLAR BORDA, Luis. Estado de derecho y Estado social de derecho. Revista Derecho del Estado, n. 20, dic. 2007. p. 73-96.

26 GÓMEZ SANCHÉZ, Yolanda. Estado Constitucional y protección internacional. In: GÓMEZ SANCHÉZ, Yolanda; PÉREZ MARCOS, Regina María (Coord.). Presente, pasado y futuro de los DDHH. Ciudad de México: CNDH, 2014. p. 231-280.
} 
hayan sido conculcadas algunas de estas prerrogativas, sean restituidos y reparados sus derechos y la parte ofensora se someta a un juicio en que se le responsabilice por sus $_{\text {actos. }}{ }^{27}$

\section{PRINCIPIOS PRO PERSONAE Y PROGRESIVIDAD ${ }^{28}$}

En el supuesto de que un mismo derecho fundamental esté reconocido en las dos fuentes supremas del ordenamiento jurídico, a saber, la Constitución y los tratados internacionales, la elección de la norma que será aplicable -en materia de Derechos Humanos-, atenderá a criterios que favorezcan al individuo o lo que se ha denominado principio pro personae. Según dicho criterio interpretativo, en caso de que exista una diferencia entre el alcance o la protección reconocida en las normas de estas distintas fuentes, deberá prevalecer aquella que represente una mayor protección para la persona o que implique una menor restricción. ${ }^{29}$ En esta lógica, el catálogo de derechos fundamentales no se encuentra limitado a lo prescrito en el texto constitucional, sino que también incluye a todos aquellos derechos que figuran en los tratados internacionales ratificados por el Estado.

En este contexto, desde el campo doctrinal se ha considerado que el referido principio "pro homine" tiene dos variantes: a) Directriz de preferencia interpretativa, por la cual se ha de buscar la interpretación que optimice más un derecho constitucional. Esta variante, a su vez, se compone de: 1.) Principio favor libertatis, que postula la necesidad de entender al precepto normativo en el sentido más propicio a la libertad en juicio, e incluye una doble vertiente: i) las limitaciones que mediante ley se establezcan a los derechos humanos no deberán ser interpretadas extensivamente, sino de modo restrictivo; $y$, ii) debe interpretarse la norma de la manera que optimice su ejercicio; 2.) Principio de protección a víctimas o principio favor debilis; referente a que en la interpretación de situaciones que comprometen derechos en conflicto, es menester considerar especialmente a la parte situada en inferioridad de condiciones, cuando las partes no se encuentran en un plano de igualdad; $y, 3$ ) Directriz de preferencia de normas, la cual prevé que el Juez aplicará la norma más favorable a la persona, con independencia de la jerarquía formal de aquélla. ${ }^{30}$

El principio de progresividad estuvo originalmente vinculado a los derechos económicos, sociales y culturales (DESC), porque se estimaba que éstos imponían a los Estados, obligaciones positivas de actuación que implicaban el suministro de recursos

\footnotetext{
27 PICARD DE ORSINI, Marie; USECHE, Judith. Una nueva dimensión del Estado de Derecho: el Estado Social de Derecho. Provincia, Mérida, número especial, p. 189-218, 2006. p. 189-218.

28 Vid, MEDELLÍN, Ximena. Principio Pro persona. Ciudad de México: Suprema Corte de Justicia de la Nación, 2013.

29 Principio pro personae. Criterio de selección de la norma de derecho fundamental aplicable.

30 Principio pro homine. Variantes que lo componen.
} 
económicos y que su plena realización estaba condicionada por las circunstancias económicas, políticas y jurídicas de cada país. ${ }^{31}$ Así, en los primeros instrumentos internacionales que reconocieron estos derechos, se incluyó el principio de progresividad con la finalidad de hacer patente que esos derechos no constituyen meros "objetivos programáticos", sino genuinos Derechos Humanos que imponen obligaciones de cumplimiento inmediato a los Estados, como la de garantizar niveles mínimos en el disfrute de esos derechos, garantizar su ejercicio sin discriminación, y la obligación de tomar medidas deliberadas, concretas y orientadas a su satisfacción; así como obligaciones de cumplimiento mediato que deben ser acometidas progresivamente en función de las circunstancias específicas de cada país. ${ }^{32}$

Así, la progresividad constituye el compromiso de los Estados para adoptar providencias, tanto a nivel interno como mediante la cooperación internacional, especialmente económica y técnica, para lograr progresivamente la plena efectividad de los derechos que se derivan de las normas económicas, sociales y sobre educación, ciencia y cultura, principio que no puede entenderse en el sentido de que los gobiernos no tengan la obligación inmediata de empeñarse por lograr la realización íntegra de tales derechos, sino en la posibilidad de ir avanzando gradual y constantemente hacia su más completa realización, en función de sus recursos materiales; así, este principio exige que a medida que mejora el nivel de desarrollo de un Estado, mejore el nivel de compromiso de garantizar los derechos económicos, sociales y culturales. $^{33}$

El Estado tiene el mandato constitucional de realizar todos los cambios y transformaciones necesarias en la estructura económica, social, política y cultural del país, de manera que se garantice que todas las personas puedan disfrutar de sus Derechos Humanos. ${ }^{34}$ Por tanto, el principio de progresividad exige a todas las autoridades del Estado, en el ámbito de su competencia, incrementar el grado de tutela en la promoción, respeto, protección y garantía de los DDHH y también les impide, en virtud de su expresión de no regresividad, adoptar medidas que sin plena justificación constitucional disminuyan el nivel de la protección a los $\mathrm{DDHH}$ de quienes se someten al orden jurídico del Estado. ${ }^{35}$

\footnotetext{
31 ARANGO, Rodolfo. Jurisprudencia constitucional sobre el derecho mínimo vital. Bogotá: Universidad de los Andes, 2002. p.16.

32 Principio de progresividad. Es aplicable a todos los derechos humanos y no sólo a los llamados económicos, sociales y culturales.

33 Principios de universalidad, interdependencia, indivisibilidad y progresividad de los derechos humanos.

34 SARLET, Ingo Wolfgang. Mínimo existencial y justicia constitucional. Recurso electrónico consultado: <https://archivos.juridicas.unam.mx/www/bjv/libros/8/3977/29.pdf>. Acceso en: 3 sept. 2018.

35 Principio de progresividad de los derechos humanos. Su naturaleza y función en el Estado mexicano.
} 


\section{EXIGIBILIDAD Y JUSTICIABILIDAD DE LOS DERECHOS HUMA- NOS}

La exigibilidad es una solicitud a la autoridad, para realizar un acto que tutele, proteja o respete un derecho. ${ }^{36}$ Esta exigibilidad es un acto en que se excita a la autoridad un proceder, y en que se pone de manifiesto que se está violando o incumpliendo un $\mathrm{DDHH}$. Ante este acto de exigibilidad, el operador jurídico estudiará el fondo del pedimento. Ante esto, se emitirá una decisión para hacer, otorgar, permitir, respetar, entre otros; que valide y consienta el uso y goce de sus $\mathrm{DDHH} .{ }^{37}$

Esta exigibilidad como se hizo notar está acompañada de la justiciabilidad, para que sea efectiva. ${ }^{38}$ Esto implica la acción del poder público para que determine, si hay violación a los derechos que expone el quejoso, o descalificar la misma, por no contar con elementos de forma o de fondo de dicha petición. Entre los elementos para concederla, sin previo estudio de fondo podría ser la irreparabilidad por el daño ocasionado, lo que da efecto a una medida cautelar, una suspensión del acto o la protección temporal, mientras se resuelve de fondo el asunto principal. ${ }^{39}$

También se debe observar que la exigibilidad y justiciabilidad en materia de DDHH no implican gratuidad sin cortapisa. Que, si bien se reconoce y protege el DDHH, no puede resultar un factor para obtener un bien o servicio sin costo económico. Esto que implica, que el reconocimiento de los DDHH no debe significar una puerta para el abuso en los derechos que presta el Estado (como podría ser temas en materia de salud, educación, agua, energía eléctrica, entre otros), en el que la población como receptores de un servicio, reconoce su obligación de realizar una contribución económica por el bien suministrado, sin importar si proviene de una empresa pública o privada. ${ }^{40}$

La posibilidad de ganar servicios o derechos de manera gratuita con base a los DDHH pudiera ser o parecer un acto para conseguir ventaja o abuso del sistema normativo. Por lo que se debe considerar cada solicitud, y resolver ante las circunstancias y el contexto en que se haga. ${ }^{41}$

36 KOJÉVE, Alexandre. La noción de autoridad. Buenos Aires: Nueva visión, 2005. p. 36.

37 CARMONA CUENCA, Encarna. Los derechos sociales de prestación y el derecho a un mínimo vital. Anuario multidisciplinar para la modernización de las administraciones públicas, Sevilla, n. 2, p. 173-197, 2006. p. 187.

38 LINZ, Juan J. Problems of democratic transition and consolidation. Baltimore: The Johns Hopkins University, 1996. p.5 y ss.

39 STA 175, Rel. Min. Gildar Mendes, enjuiciada el 17.03.2010.

40 SARLET, Ingo Wolfgang. Mínimo existencial y justicia constitucional. Recurso electrónico consultado: <https://archivos.juridicas.unam.mx/www/bjv/libros/8/3977/29.pdf>. Acceso en: 3 sept. 2018. Estos Ilamados "triunfos" son acuñación de Ronald Dworkin, que advierte que los derechos obtenidos, son triunfos de movimientos sociales o políticos. Los derechos en serio, Ed.Abelot-Perrot, Argentina, 1996.

41 WALDRON, Jeremy. Law and disagreement. Mississippi: Oxford University Press, 2004. p.5, 21-48. 
Hay que entender y razonar que los derechos prestacionales exigidos como DDHH no son un cheque en blanco. Sino que hay que ponderarlos, según sea el caso, aplicando un test para considerar su exigibilidad, reconocer su justiciabilidad y otorgarse este derecho. Para este proceso, se propone un control que calificará si el Estado debe dar, entregar o realizar un acto para tutelar algún DDHH. Con esto, se cuidaría y construiría un sistema jurídico justo, prístino e imparcial. ${ }^{42}$

Debo puntualizarse que la limitación en el cumplimiento de un Derecho Humano no necesariamente es sinónimo de vulneración, pues para determinar si una medida lo respeta, es necesario analizar si: (I) dicha disminución tiene como finalidad esencial incrementar el grado de tutela de un derecho humano; y (II) generar un equilibrio razonable entre los derechos fundamentales en juego, sin afectar de manera desmedida la eficacia de alguno de ellos. En ese sentido, para determinar si la limitación al ejercicio de un derecho viola el principio de progresividad de los derechos humanos. El operador jurídico debe realizar un análisis conjunto de la afectación individual de un derecho en relación con las implicaciones colectivas de la medida, a efecto de establecer si se encuentra justificada..$^{43}$

\section{6. ¿CUMPLIMIENTO INCONDICIONAL, INTRINSECO Y ABSOLUTO?}

Lo primero que se debe considerar, es colocar un contexto para los DDHH o sea, determinarlos dentro de un sistema normativo. ${ }^{44}$ Los DDHH son vistos como un eje rector del Estado, pero que podrían sobreponerse al resto del ordenamiento nacional. Esto nos origina dos supuestos: el que se concedan de manera casi automática por su peso moral, aun cuando demerite o mengue algún derecho prestacional o fundamental, que tiene una regulación para hacerlo efectivo. ${ }^{45} \mathrm{O}$ ponderar si la tutela o protección que se solicita, colisiona con derechos ya sea sustantivos o adjetivos, haciéndose notar que esa determinación, creará un precedente administrativo y/o jurisdiccional. ${ }^{46}$

42 Esta misma interpretación se reitera en las SSTC 134/1989 y 140/1989, ambas de 20 de julio. En la jurisprudencia del Tribunal Constitucional Federal alemán también podemos encontrar un reconocimiento tácito del derecho a un mínimo vital, en opinión de Robert Alexy, si se consideran conjuntamente dos sentencias de los años 1951 y 1975 (BverfGE 1, 97 y BverfGE 40, 121). Vid., del autor, ALEXY, Robert. Teoría de los derechos fundamentales. Madrid: Centro de estudios constitucionales, 2007. p. 422-423.

43 Principio de progresividad de los derechos humanos. Criterios para determinar si la limitación al ejercicio de un derecho humano deriva en la violación de dicho principio.

44 En el caso de México, son parte integrante del andamiaje legal, y se encuentran por debajo de la constitución nacional. Derechos humanos contenidos en la constitución y en los tratados internacionales. constituyen el parámetro de control de regularidad constitucional, pero cuando en la constitución haya una restricción expresa al ejercicio de aquéllos, se debe estar a lo que establece el texto constitucional.

45 HART, H.L.A. The concept of law. Oxford: Clarendon, 1988. p. 7; 14.

46 VANOSSI, Jorge Reinaldo. El Estado de derecho en el constitucionalismo social. Buenos Aires: EUDEBA, 1987. p.146. 
¿Pero es más importante tutelar y proteger los DDHH, que la propia Constitución? ${ }^{47}$ Pues todo depende de dos factores, el operador jurídico (funcionario o juez) y el contexto en que se realiza el acto. En el primer caso, la conducta del operador jurídico podrá ser la de un garantista que maximice los derechos de las personas y restringa la acción del Estado, garantizando los $\mathrm{DDHH}$, de manera automática, impronta e indubitable. En el que su juicio o realización sea para no entrar a la cuestión de fondo, o si considera que se debe tutelar y proteger ese Derecho Humano, sin importar otras consideraciones. La sola exigibilidad asegura su justiciabilidad en este modelo, que llamare: reacción positiva. En el otro modelo, se tendrá en consideración ciertos elementos como: la gradualidad; si hay peligro vital; se restringe alguna libertad; si es sine qua non para poder desarrollarse como persona; si la negación atentase contra su dignidad, que nombrare como: ponderación mínima.

\section{CASOS DE ESTUDIO}

En el siguiente apartado, se presentarán y analizarán diversos asuntos en que los solicitantes exigieron la protección constitucional de sus $\mathrm{DDHH}$, para que pudieran acceder a varios bienes o servicios que presta el Estado o empresas particulares, sin ningún costo, y poder tener una vida digna o realizarse libremente su personalidad. ${ }^{48}$ Asimismo, se adjuntan los casos legales y criterios jurisprudenciales más relevantes sobre cada uno de los temas expuestos, para exponer la interpretación que hacen de cada Derecho Humano, y como decidieron que se debían proteger estos. ${ }^{49}$

\subsection{Derecho a la salud sin costo al paciente}

El primer caso que se analizará sucedió en México, en el que unos elementos pertenecientes a la Secretaria de Marina (SEMAR) fueron despedidos por que se conoció que tenían la infección del virus de la inmunodeficiencia humana (VIH). La Ley del Instituto de Seguridad Social para las Fuerzas Armadas Mexicanas (ISSFAM) de esa época fue el medio para resolver este entuerto.

Ahora, resulta conveniente indicar que dentro de las funciones principales del ISSFAM, deben suministrar prestaciones de carácter social, económico y de salud a los militares en activo, en situación de retiro, a sus derechohabientes, a los pensionistas y a los beneficiarios.

\footnotetext{
47 BICKEL, Alexander M. The least dangerous power. New Haven: Yale University Press, 1986. p. 23-33, 58-59 у 199.

48 ELSTER, Jon. Explaining social behavior. Cambridge: Cambridge, 2007. p. 179 y ss.

49 PICARD DE ORSINI, Marie; USECHE, Judith. Una nueva dimensión del Estado de Derecho: el Estado Social de Derecho. Provincia, Mérida, número especial, p. 189-218, 2006. p. 189-218.
} 
Pero al conocerse la condición de los elementos de la Marina fueron separados de sus funciones, y luego dados de baja sin una causa justificada. También determinaron la Institución que no debían de cuidar su derecho a la salud, por no ser una enfermedad adquirida por el desarrollo de sus labores.

En el desarrollo del tema, la Suprema Corte de Justicia de la Nación (SCJN) analizó el contenido y el alcance que tienen para el caso concreto las garantías de igualdad, de no discriminación y de acceso a la salud.

Asimismo, la Corte consideró pertinente aludir a los alcances de la garantía de discriminación en el sentido de que la Constitución instituye que todos los hombres son iguales ante la ley sin que pueda prevalecer discriminación alguna por razón de nacionalidad, raza, sexo, religión o cualquier otra condición o circunstancia personal o social, de manera que los poderes públicos han de tener en cuenta que los particulares que se encuentren en la misma situación deben ser tratados igualmente, sin privilegio ni favor. De esta forma, el principio de igualdad dispone que este es uno de los valores superiores del orden jurídico, lo que significa que ha de servir de criterio básico para la producción normativa y su posterior interpretación y aplicación.

Sin embargo, se consideró que debía tenerse en cuenta que no toda desigualdad de trato o exclusión se traduce en un acto discriminatorio, en tanto es necesario que tales actos afecten la dignidad de las personas o tengan como resultado, restringir o anular sus derechos y libertades.

En adición a lo anterior, se tomó en cuenta que al reconocer en los Tratados Internacionales la posibilidad de ampliar el catálogo de derechos fundamentales, particularmente, en el caso, los que se relacionan con las personas que padecen una disminución física, psíquica o sensorial, y en ese entendido se retomaron los contenidos de la normatividad internacional sobre la materia y estableció una especial protección para ese grupo de personas.

Para dar respuesta a los argumentos esgrimidos, se determinó que en ningún momento se privó a los quejosos de alguna de las garantías previstas en la Constitución por la circunstancia de que se tomen o no en cuenta los años de servicio por el solo hecho de establecerse en la ley distintos requisitos para los sistemas de seguridad social un militar en las condiciones de salud que narra el solicitante, éste siendo sometido a un trato que afecte su dignidad humana.

Se consideró que de darse alguna violación con respecto a la dignidad humana ésta sería por contravenir al derecho de protección de la salud o el mandato de no discriminación, pero no, como sucedía en los casos analizados, por la existencia o inexistencia de mayores o menores requisitos en la ley para otorgar el derecho a recibir asistencia médica y suministro de medicamentos, máxime si se trataban de requisitos fundados objetivamente. En el caso, la distinción establecida respecto al número de años exigidos en cada régimen de seguridad social se vinculó con la diferenciación que 
de éstos se hizo en la Constitución, refiriéndose a las leyes de seguridad social aplicables a la población abierta de las que se ocupan de quienes pertenecen al ejército. Por tanto, dicha finalidad se consideró constitucionalmente admisible.

Los accionantes de los distintos juicios aludieron que se trasgredieron en su perjuicio las garantías individuales consagradas en la Constitución, pues fueron objeto de discriminación por motivo de condiciones de salud. se observó la preferencia del interés constitucional de eficacia de las fuerzas armadas y protección de la integridad de sus miembros y de terceros, frente al interés del militar diagnosticado con alguna infección recurrente atribuibles a estados de inmunodeficiencias, en el caso VIH, quién pese a ello está respaldado por las garantías de igualdad y no discriminación por razón de salud, inclusive al grado de hacer posible el retiro definitivo del militar respectivo, la consecuente eliminación de sus percepciones y la sustracción de los beneficios de seguridad social que ordinariamente le corresponderían en activo.

El Sistema de Protección Social en Salud debe estar previsto para las personas que no sean derechohabientes de las instituciones de seguridad social o no cuenten con algún otro mecanismo de previsión social en salud, será financiado de manera solidaria por la Federación, los Estados, el Distrito Federal y los propios beneficiarios, excepto cuando "exista la incapacidad de la familia" para cubrir la cuota relativa, en el sentido de que no impedirá a los enfermos incorporarse y ser sujetos de los beneficios que se deriven del Sistema de Protección Social en Salud.

De lo expuesto, se concluyó en la sentencia respectiva que la garantía de acceso a la salud pone en responsabilidad del Estado el establecimiento de los mecanismos necesarios para que todos los mexicanos tengan acceso a los servicios de salud, en la cual encontramos la asistencia médica y el suministro de medicamentos, y a su vez se encuentran los diversos regímenes de seguridad social.

Como argumento relativo al caso, se comentó la facultad de exigir a una determinada institución la prestación de servicios de salud no se entiende derivada directamente del mandato constitucional, sino que requiere la necesaria existencia de una ley que habilite el ejercicio de este derecho cuya creación se encuentra asignada al legislador ordinario. De esta manera el Máximo Órgano Jurisdiccional resolvió un tema de suma importancia respecto a las garantías de igualdad, no discriminación y derecho a la salud previstas en la Constitución.

Asimismo, la SCJN ha generado diversas tesis jurisprudenciales en que reconoce la importancia y valor del derecho a la salud. Se parte de la premisa de que, aunque en un Estado constitucional democrático el legislador ordinario y las autoridades gubernamentales y administrativas tienen un margen muy amplio para plasmar su visión de la Constitución y, en particular, para desplegar en una dirección u otra las políticas públicas y regulaciones que deben dar cuerpo a la garantía efectiva de los 
derechos, ${ }^{50}$ el Juez Constitucional puede contrastar su labor con los estándares contenidos en la propia Ley Suprema y en los Tratados de Derechos Humanos que forman parte de la normativa y vinculan a todas las autoridades estatales. ${ }^{51}$

La Corte ha señalado que el derecho a la protección de la salud previsto en el citado precepto constitucional tiene, entre otras finalidades, la de garantizar el disfrute de servicios de salud y de asistencia social que satisfagan las necesidades de la población, y que por servicios de salud se entienden las acciones dirigidas a proteger, promover y restaurar la salud de la persona y de la colectividad. Así, lo anterior es compatible con varios instrumentos internacionales de derechos humanos, entre los que destacan el apartado $1^{\circ}$ del artículo $25^{\circ}$ de la Declaración Universal de los Derechos Humanos, que señala que toda persona tiene derecho a un nivel de vida adecuado que le asegure, así como a su familia, la salud y el bienestar y en especial la alimentación, el vestido, la vivienda, la asistencia médica y los servicios sociales necesarios; el artículo $12^{\circ}$ del Pacto Internacional de Derechos Económicos, Sociales y Culturales, que alude al derecho de toda persona al disfrute del más alto nivel posible de salud física y mental, y refiere que los Estados deben adoptar medidas para asegurar la plena efectividad de este derecho; y el artículo $10^{\circ}$ del Protocolo Adicional a la Convención Americana sobre Derechos Humanos en materia de Derechos Económicos, Sociales y Culturales "Protocolo de San Salvador", según el cual toda persona tiene derecho a la salud, entendida como el disfrute del más alto nivel de bienestar físico, mental y social. En ese sentido y en congruencia con lo establecido por el Comité de Derechos Económicos, Sociales y Culturales de las Naciones Unidas, el derecho a la salud debe entenderse como una garantía fundamental e indispensable para el ejercicio de los demás derechos humanos y no sólo como el derecho a estar sano.

Asimismo, la protección del derecho a la salud incluye, entre otras, las obligaciones de adoptar leyes u otras medidas para velar por el acceso igual a la atención de la salud y los servicios relacionados con ella; vigilar que la privatización del sector de la salud no represente una amenaza para la disponibilidad, accesibilidad, aceptabilidad y calidad de los servicios; controlar la comercialización de equipo médico y medicamentos por terceros, y asegurar que los facultativos y otros profesionales de la salud reúnan las condiciones necesarias de educación y experiencia; de ahí que el derecho a la salud debe entenderse como un derecho al disfrute de toda una gama de facilidades, bienes, servicios y condiciones necesarios para alcanzar el más alto nivel posible de salud. ${ }^{52}$

\footnotetext{
50 SALAZAR, Pedro. Justicia constitucional y democracia. In: VÁZQUEZ, Rodolfo (Coord.). Corte, jueves y política. Ciudad de México: Fontamara, 2007. p.39.

51 Derecho a la salud. Su naturaleza normativa.

52 Derecho a la salud. Su regulación en el artículo $4^{\circ}$ de la Constitución política de los Estados Unidos Mexicanos y su complementariedad con los Tratados Internacionales en materia de Derechos Humanos.
} 
El Sistema de Protección Social en Salud prevé para las personas que no sean derechohabientes de las instituciones de seguridad social o no cuenten con algún otro mecanismo de previsión social en salud, que será financiado de manera solidaria por la Federación, los Estados y los propios beneficiarios mediante cuotas familiares que se determinarán atendiendo a las condiciones socioeconómicas de cada familia, sin que el nivel de ingreso o la carencia de éste sea limitante para acceder a dicho sistema. Lo anterior permite advertir que el derecho a la protección de la salud se traduce en la obligación del Estado de establecer los mecanismos necesarios para que todas las personas tengan acceso a los servicios de salud y que en virtud de que ésta es una responsabilidad que comparten el Estado, la sociedad y los interesados, el financiamiento de los respectivos servicios, no corre a cargo del Estado exclusivamente, pues incluso, se prevé el establecimiento de cuotas de recuperación a cargo de los usuarios de los servicios públicos de salud y del sistema de protección social en salud, que se determinan considerando el costo de los servicios y las condiciones socioeconómicas de los usuarios, eximiéndose de su cobro a aquellos que carezcan de recursos para cubrirlas, de ahí que la salud sea una responsabilidad que comparten indisolublemente el Estado, la sociedad y los interesados, con base en criterios de capacidad contributiva y redistribución del ingreso. ${ }^{53}$

Asimismo, la SCJN ha señalado que el artículo $2^{\circ}$ del Pacto Internacional de Derechos Económicos, Sociales y Culturales establece obligaciones de contenido y de resultado; aquéllas, de carácter inmediato, se refieren a que los derechos se ejerciten sin discriminación y a que el Estado adopte dentro de un plazo breve medidas deliberadas, concretas y orientadas a satisfacer las obligaciones convencionales, mientras que las de resultado o mediatas, se relacionan con el principio de progresividad, el cual debe analizarse a la luz de un dispositivo de flexibilidad que refleje las realidades del mundo y las dificultades que implica para cada país asegurar la plena efectividad de los DESC. ${ }^{54}$ En esa lógica, teniendo como referente el derecho de toda persona al disfrute del más alto nivel posible de salud física y mental contenido en el artículo $12^{\circ}$ del citado Pacto, se impone al Estado, por una parte, la obligación inmediata de asegurar a las personas, al menos, un nivel esencial del derecho a la salud y, por otra, una de cumplimiento progresivo, consistente en lograr su pleno ejercicio por todos los medios apropiados, hasta el máximo de los recursos de que disponga. De ahí que se configurará una violación directa a las obligaciones del Pacto cuando, entre otras cuestiones, el Estado no adopte medidas apropiadas de carácter legislativo, administrativo, presupuestario, judicial o de otra índole, para dar plena efectividad al derecho indicado. ${ }^{55}$

\footnotetext{
53 Salud. El derecho a su protección conforme al artículo 4º, tercer párrafo, de la Constitución política de los Estados Unidos Mexicanos, es una responsabilidad social.

54 Vid, CERVANTES, Magdalena. ¿Hay justicia para los DESC? Ciudad de México: UNAM, 2014.

55 Salud. Derecho al nivel más alto posible. Éste puede comprender obligaciones inmediatas, como de cumplimiento progresivo.
} 
También, la Corte ha ampliado la protección de la salud como derecho fundamental del que el Estado está obligado a garantizar; y que está tutelado en la Constitución, el artículo $25^{\circ}$ de la Declaración Universal de los Derechos Humanos, $12^{\circ}$ del Pacto Internacional de Derechos Económicos, Sociales y Culturales y $10^{\circ}$ del Protocolo Adicional a la Convención Americana sobre Derechos Humanos en Materia de Derechos Económicos, Sociales y Culturales, de los cuales se advierte que los servicios básicos de salud consisten, entre otros aspectos, en la disponibilidad de medicamentos y otros insumos esenciales para la salud, para cuyo efecto habrá un cuadro básico y catálogo de insumos del sector salud. No obstante, no debe entenderse como un impedimento o una restricción para los beneficiarios de las dependencias y entidades que prestan el servicio de protección de la salud, el hecho de que algún medicamento no esté incluido en ese cuadro básico. Por tanto, atento a la visión progresiva con la que deben apreciarse los derechos fundamentales del gobernado, dichas dependencias y entidades, entre las que se encuentra el suministrar a sus beneficiarios esos medicamentos, aun cuando no estén en ese cuadro básico, siempre que exista una prescripción médica que lo avale. ${ }^{56}$

\subsection{Educación superior gratuita}

La educación es una de las metas de la agenda con objetivos de desarrollo de las Naciones Unidas al 2030. Es un elemento clave para el progreso sostenible de las naciones. Con la educación se busca alcanzar el pleno desarrollo de las personas, en todas y cada una de las etapas de su vida, de manera que no se agota al culminar los estudios básicos, tiene un alcance progresivo y permanente en mujeres y hombres con la finalidad de perfeccionar sus capacidades, habilidades y destrezas, para alcanzar su máximo desarrollo.

Esta idea la vemos reflejada en los Tratados Internacionales suscritos y ratificados por el Estado, como la Declaración Universal de Derechos Humanos (Art. XII), la Declaración Americana de Derechos y Deberes del Hombre (Art. 12), el Pacto Internacional de Derechos Económicos, Sociales y Culturales (Art. 13\%), la Convención Americana sobre Derechos Humanos (Art. 26ㅇ) , la Convención de los Derechos del Niño (Art. 28), Convención sobre los Derechos de la Personas con Discapacidad (Art. 24\%) o el Convenio número 169 de la Organización Internacional del Trabajo sobre los Derechos de los Pueblos Indígenas y Tribales (Arts. $26^{\circ}, 27^{\circ}$ y $\left.29^{\circ}\right) .^{57}$

56 El Instituto Mexicano del Seguro Social debe suministrar a sus beneficiarios los medicamentos que se les prescriban, aun cuando no estén incluidos en el cuadro básico y catálogo de insumos del sector salud.

57 En la actualidad se ha ampliado el alcance del derecho a la educación con nuevas interpretaciones judiciales. Aquí destacan los casos en que se determinó que una institución privada puede considerarse autoridad responsable para efectos de la protección constitucional; sobre la obligación de las instituciones educativas de evitar situaciones de violencia y discriminación; respecto de los compromisos asumidos por el Estado para garantizar educación a las personas; $y$, por el derecho a la educación bilingüe o multilingüe de las personas indígenas. Amparo en revisión (AR) 35/2014. 
En distintas ocasiones, ${ }^{58}$ la SCJN ha emitido resoluciones contra instituciones privadas de educación; recientemente en el estado de Chiapas ${ }^{59}$ se dictó una sentencia, que determinó que una universidad privada sí puede ser considerada autoridad responsable. Se señaló procedente el amparo contra particulares, cuando aquellos crean, modifican o extingan situaciones jurídicas en forma unilateral y obligatoria, con base en una concesión otorgada por el Estado para ejercer esa función, de tal manera que se asimila al servicio que en su lugar brindaría el ente público, sin que para ello sea necesario que forme parte de un ente estatal.

Respecto de la educación como obligación del Estado. ${ }^{60}$ la Corte estableció que el Estado debe adoptar políticas públicas que permitan a todo ser humano recibir la formación, instrucción, dirección o enseñanza necesarias para el desarrollo armónico de todas sus capacidades cognoscitivas, intelectuales, físicas y humanas, como elemento principal en la formación de su personalidad y que para hacerlo efectivo tienen que cumplir obligaciones como la capacitación de las personas para participar en una sociedad libre, impartirse por las instituciones o por el Estado de forma gratuita y ajena de toda discriminación. Asimismo, estableció que la educación debe tener las siguientes características: disponibilidad, accesibilidad, aceptabilidad y adaptabilidad. Es decir, la Corte determinó que el derecho a la educación es una estructura compleja a cargo de las autoridades con obligaciones impuestas que deben cumplirse.

Las resoluciones del Poder Judicial han sentado precedentes que han abierto el camino hacia una revisión de las políticas públicas o el funcionamiento de los sistemas educativos y ha generado transformaciones en la aplicación del derecho a la educación.

En otro asunto, una estudiante de la Universidad Michoacana de San Nicolás Hidalgo (UMSNH), obtuvo un amparo de la Suprema Corte de Justicia de la Nación (SCJN) que garantizó la gratuidad de su educación hasta que concluya su licenciatura. ${ }^{61}$

La ciudadana impugnó la constitucionalidad del Acuerdo del Consejo Universitario que determinaba que a partir del ciclo escolar 2014 los alumnos de educación media superior y superior debían cubrir cuotas de inscripción o reinscripción en sus respectivas escuelas y facultades. Inconforme, la alumna recurrió a la protección constitucional contra el acuerdo por considerar que violenta el Derecho Humano a la educación y el principio de progresividad. Se basó en el Artículo $138^{\circ}$ de la Constitución de Michoacán de Ocampo, que establece que la educación superior impartida por la entidad será gratuita, y en Artículo $1^{\circ}$ de la Constitución Federal que estipula el deber de respetar los DDHH de conformidad, entre otros, con el principio de progresividad.

58 AR 78/2014, AR 323/2014, Incidente de suspensión 87/2015, Queja 213/2015, AR 261/2015.

59 Amparo 902/2016.

$60 \quad$ AR 323/2014.

61 AR 1374/2015. 
Por lo que se concedió el amparo a la estudiante a efecto de desincorporar de su esfera jurídica la obligación de cubrir las cuotas en los subsecuentes ciclos escolares. Sin embargo, el rector y el tesorero de la Universidad interpusieron la revisión del amparo.

Al resolver el recurso, la Corte confirmó la sentencia recurrida y amparó a la estudiante al considerar que los actos reclamados "violaron su Derecho Humano a la educación previsto en el Artículo $3^{\circ}$ de la Constitución Federal y desarrollado por el Artículo $138^{\circ}$ de la Constitución del Estado de Michoacán".

También determinó que se violó el principio de progresividad, porque "las autoridades responsables no demostraron fehacientemente la ausencia de recursos económicos para garantizar la gratuidad de la educación superior impartida por el estado de Michoacán, ni que hubieran realizado todos los esfuerzos posibles para obtenerlos".

Los jueces de la Suprema Corte precisaron que la autonomía universitaria no exime a la Universidad de respetar el derecho a la gratuidad de la educación superior reconocido por la Constitución local, ya que dicha figura "constituye una garantía institucional del derecho a la educación cuya finalidad es maximizarlo, no restringirlo". Además, indicó que, en virtud del principio de progresividad, una vez que dicha entidad ha extendido la gratuidad a la educación superior tiene prohibido adoptar medidas regresivas.

Al conceder la protección constitucional a la estudiante, el gobernador del estado estará obligado a transferir a la Universidad Michoacana los recursos necesarios para garantizar la gratuidad de la educación que reciba la quejosa hasta el nivel licenciatura, lo que incluye, al menos, los recursos necesarios para cubrir las cuotas de inscripción.

En tanto, la Universidad y sus autoridades deberán abstenerse de vulnerar la gratuidad de la educación superior que reciba la estudiante, es decir, evitar, como mínimo, cobrarle las cuotas de inscripción durante su educación superior.

La SCJN ha configurado en el artículo $3^{\circ}$ constitucional un contenido mínimo del derecho a la educación que el Estado Mexicano está obligado a garantizar con efecto inmediato; contenido que puede y debe ser extendido gradualmente por imperativo del principio de progresividad.

En efecto, se puede establecerse la gratuidad de la educación en virtud del principio de progresividad; $y$, además, debe respetar otros principios como el de acceso sobre la base de las capacidades y la no discriminación en el acceso, permanencia y conclusión, entre otros. ${ }^{62}$

Asimismo, en el artículo $1^{\circ}$ de la Constitución mexicana establece que las principales fuentes de reconocimiento de DDHH son la propia Constitución y los Tratados Internacionales. El Derecho Humano a la educación está reconocido tanto en los artículos $3^{\circ}$ y $4^{\circ}$ de la Constitución, como en diversos instrumentos internacionales, entre los

62 Derecho a la educación. Su configuración mínima es la prevista en el artículo $3^{\circ}$ Constitucional. 
que destacan los artículos XII de la Declaración Americana de los Derechos y Deberes del Hombre; 13 del Pacto Internacional de Derechos Económicos, Sociales y Culturales; $13^{\circ}$ del Protocolo adicional a la Convención Americana Sobre Derechos Humanos en materia de Derechos Económicos, Sociales y Culturales, "Protocolo De San Salvador"; y $28^{\circ}$ de la Convención sobre los Derechos del Niño. Las normas citadas coinciden en lo esencial, entre otras cosas, en lo relativo a que la titularidad del derecho a la educación es de toda persona; en que el contenido de la educación básica debe estar orientado a posibilitar la autonomía de sus titulares y a habilitarlos como miembros de una sociedad democrática; en que la enseñanza básica debe ser asequible a todos sin discriminación, de manera obligatoria, universal y gratuita, y el Estado debe garantizarla; y en que los padres tienen derecho a elegir la educación que se imparta a sus hijos y los particulares a impartirla, siempre y cuando respeten el contenido mínimo de ese derecho. ${ }^{63}$

Ahora, si bien la configuración mínima del derecho a la educación pública superior, prevista en la Constitución Federal, no establece que el Estado deba proveer de manera gratuita la educación superior, sino sólo el de promoverla para lograr distintos objetivos colectivos necesarios para el desarrollo de la Nación, lo cierto es que el Estado asumió el deber de extender la gratuidad también a la educación superior, de acuerdo con el principio de progresividad previsto en el artículo $1^{\circ}$ Constitucional y en las diversas normas internacionales, así como en el compromiso asumido en el artículo $13^{\circ}$, número 2, inciso c), del Pacto Internacional de Derechos Económicos, Sociales y Culturales, y en el artículo $13^{\circ}$, número 2, inciso c), del Protocolo adicional a la Convención Americana sobre Derechos Humanos en materia de Derechos Económicos, Sociales y Culturales, "Protocolo de San Salvador", que establecen que debe implantarse progresivamente la enseñanza superior gratuita. ${ }^{64}$

En estos negocios, el poder judicial no estimó considerar las condiciones económicas de los solicitantes y, tampoco acordó nada adicional, para que no se produjera un futuro daño irreparable, para brindarse la educación superior.

\subsection{Suministro de agua gratuito}

En el año 2017, en el estado de Tamaulipas, México, una persona solicitó la gratuidad en el suministro de agua potable. En este caso procedió la cancelación del suministro del líquido vital por la falta de pago ante el cobro ilegal del servicio; por lo que la recurrente se amparó contra el acto de autoridad por omitir el acceso al agua potable, que en su perspectiva conculcaba sus DDHH. En la sentencia se anota, que el derecho

63 Derecho fundamental a la educación. Su referente normativo en el sistema jurídico mexicano.

64 Derecho a la educación pública superior. El estado mexicano tiene la obligación de implantar progresivamente su gratuidad. 
al agua comprende la garantía de acceso al líquido vital, razón por la cual se ha establecido varios mecanismos para que todas las personas puedan contar con este. ${ }^{65}$

Con motivo de su especial importancia, el acceso al agua ha sido el centro de múltiples instrumentos internacionales llevados a cabo con el propósito fundamental de garantizar una distribución mínima indispensable, así, por su parte en el año del 2002 el Comité de Derechos económicos, sociales y culturales de las Naciones Unidas aprobó su observación general número quince, sobre el derecho del agua, en el que lo definió de la siguiente manera: "El Derecho Humano al agua es indispensable para una vida humana digna".

También en dicha observación se conceptualizó a tal derecho como aquel a disponer de agua suficiente, saludable, aceptable, físicamente accesible y asequible para su uso personal y doméstico.

En los artículos $11^{\circ}$ y $12^{\circ}$ del Pacto Internacional de los DESC se establece el derecho fundamental a una vida digna para los individuos y su familia, que incluye alimentación vestido y la mejora continua de sus condiciones de existencia.

En su observación general número quince, el Comité de los DESC aclaró el alcance y el contenido del derecho al agua, explicando que significa disponer de agua suficiente, saludable, aceptable, físicamente accesible y asequible para su uso personal y doméstico, y que comprenden el consumo el lavado de ropa, la preparación de alimentos y la higiene personal y doméstica.

La declaración del agua como derecho deriva de la idea del recurso hídrico como un bien social y cultural, y no como un bien de carácter económico. El derecho implica además la posibilidad de tener acceso inquebrantable y con ello, un constante paso a sistemas de abastecimiento en igualdad de oportunidades para toda la comunidad, sin olvidar que paradójicamente, el mayor problema radica en la imposibilidad de acceso al agua apta para el consumo de las personas.

Para poder ejercer el derecho al agua, varía en función de distintas condiciones, por ello, en la referida observación general número quince se precisaron los factores a aplicar en cualquier circunstancia, a saber: a) Disponibilidad; b) Calidad y c) Accesibilidad.

Para la SCJN, el derecho al agua encuadra precisamente en uno de los derechos implícitos del derecho a una vida digna, es decir, a la propia dignidad de la persona como ser humano en el sentido que el Estado no puede negar de forma absoluta o total el acceso o suministro a un mínimo vital por falta de pago.

La Corte ha señalado al respecto que el artículo $11^{\circ}$, numeral 1 , del Pacto Internacional de DESC establece el derecho de toda persona a una vivienda adecuada, así como la obligación de los Estados Parte de tomar las medidas apropiadas para asegurar

65 Amparo 374/2017-b. 
su efectividad. Ahora bien, el derecho fundamental a una vivienda digna y decorosa, tiene las siguientes características: (a) debe garantizarse a todas las personas; (b) no debe interpretarse en un sentido restrictivo; (c) para que una vivienda se considere "adecuada" requiere contar con los elementos que garanticen un nivel mínimo de bienestar a quien la habite, esencialmente, una infraestructura básica adecuada, que proteja de la humedad, la lluvia, el viento, así como riesgos estructurales, con instalaciones sanitarias y de aseo, un espacio especial para preparar e ingerir los alimentos, espacio adecuado para el descanso, iluminación y ventilación adecuadas, acceso al agua potable, electricidad, y drenaje. ${ }^{66}$

Ratificando el criterio anterior, la SCJN consideró que el Comité de Derechos Económicos, Sociales y Culturales de las Naciones Unidas, la Organización Mundial de la Salud, la Asamblea General de las Naciones Unidas, el Pacto Internacional de Derechos Económicos, Sociales y Culturales (artículo 11º), reconocen el derecho al agua. En tanto que la Constitución advierte que el derecho al agua potable es fundamental e indispensable para la realización, goce y disfrute de los demás derechos humanos, cuya preservación en cantidad, calidad y sustentabilidad es tarea fundamental tanto del Estado como de la sociedad, por cuanto a que tal derecho está basado en las premisas de un acceso al bienestar de toda la población, sustentado por los principios de igualdad y no discriminación, independientemente de las circunstancias sociales, de género, políticas, económicas o culturales propias de la comunidad en la que se opera.

En este sentido, ${ }^{67}$ el Estado garantizará que el derecho al agua sea seguro, aceptable, accesible y asequible tanto para uso personal como doméstico, erigiéndose como un beneficio colectivo que debe basarse en criterios de solidaridad, cooperación mutua, equidad y en condiciones dignas, por lo que se ha proclamado de prioridad y de seguridad nacional la preferencia del uso doméstico y público urbano en relación con cualesquier otro uso, razones que excluyen la posibilidad de que pueda ser concebido atendiendo a intereses particulares o de grupos minoritarios, pues de ser así, imperaría un régimen de aprovechamiento del agua sin visión humana y social, con lo cual se atentaría contra la dignidad humana. ${ }^{68}$

También, la Corte interpretó que para obtener el servicio de agua potable se deberá tramitar ante el organismo operador el dictamen de factibilidad para la conexión a la red general de agua potable y drenaje sanitario; y, satisfechos los requisitos de factibilidad, las autoridades competentes deben construir las instalaciones y conexiones de agua potable y drenaje sanitario conforme al proyecto autorizado, así como las

\footnotetext{
66 Derecho fundamental a una vivienda digna y decorosa. Su contenido a la luz de los Tratados Internacionales.

67 Fracciones I y XXII del artículo 14 Bis 5 de la Ley de Aguas Nacionales de México.

68 Agua potable. Como Derecho Humano, la preferencia de su uso doméstico y público urbano es una cuestión de seguridad nacional.
} 
obras de infraestructura que en su caso se requieran. ${ }^{69}$ Sin embargo, los peticionarios del servicio no deben, para gozar del derecho humano a la salud, previsto en la Constitución, esperar a que se establezca la infraestructura a que se refiere el mencionado artículo, pues ante la ausencia de redes y establecida la necesidad del servicio de agua, el Estado tiene una doble obligación: La primera, prevista en el artículo $12^{\circ}$ del Pacto Internacional de Derechos Económicos, Sociales y Culturales, que lo constriñe a atender de manera inmediata el derecho a la salud en el más alto nivel posible; y, la segunda, establecida en el numeral 2 del propio pacto, que dispone que los Estados deberán adoptar todos los medios apropiados y hasta el máximo de los recursos que disponga. En esos términos, ante la falta de red o infraestructura para proporcionar el servicio de agua, las autoridades están obligadas a proporcionar de manera inmediata el vital líquido para lo cual, en tanto se construyan las redes de distribución adecuadas para asegurar el abastecimiento. ${ }^{70}$

La SCJN dispuso el Derecho Humano de acceso al agua para el consumo personal y doméstico, y establece que ese acceso debe ser en forma suficiente, salubre, aceptable y asequible. Así como que el Estado debe garantizarlo y que la ley definirá las bases, apoyos y modalidades correspondientes. También, la Corte constituyó la interpretación amplia y favorable del citado derecho. ${ }^{71}$

\section{CONCLUSIONES}

Es importante discernir sobre la explotación de los derechos prestacionales exigidos como DDHH. Esto ha producido diversos abusos por los recurrentes, por lo que es preciso contar con límites para su otorgamiento, más no para su reconocimiento. ${ }^{72}$

Este artículo propone que no haya parcialidad administrativa o judicial per se, cuando una persona reclama un DDHH. Los Derechos Humanos tienen una fundamentación moral; sin embargo, los derechos que presta un Estado se basan en un binomio derecho/obligación que debe cumplir toda la población. Ahora, la justificación de que

\footnotetext{
69 Artículo 34 de la Ley de Agua Potable y Saneamiento para el Estado de Nuevo León,
}

70 Derecho Humano a la provisión de agua potable. La obligación de proporcionarla es una obligación del Estado que se debe realizar de forma inmediata, aun y cuando no exista red general ni se haya efectuado el dictamen de factibilidad. La autoridad judicial puede provisionalmente indicar métodos generalmente utilizados con ese propósito, tal como la instalación de un tanque nodriza elevado y que conectado a una cisterna de reserva con bomba hidroneumática, abastezca de agua a la comunidad en cantidad y calidad; así, la propia judicatura, con apoyo en el artículo $1^{\circ}$ de la Constitución asegura y protege el derecho al suministro de agua y a la salud, como medida básica y de subsistencia que necesita el ser humano, hasta en tanto quede instalada la red de agua potable y alcantarillado.

71 Derecho humano de acceso al agua. Está reconocido constitucional y convencionalmente tanto para el consumo personal y doméstico, como para el uso agrícola o para el funcionamiento de otras áreas productivas del sector primario.

72 Vid, NINO, Carlos S. El principio de autonomía de la persona. In: NINO, Carlos S. Ética y Derechos Humanos. Buenos Aires: Astrea, 1989. p. 199-236. 
se otorgue un Derecho Humano a costa del erario debe depender del caso concreto y bajo ciertos controles, pues podría pauperizar a la Constitución.

El reconocimiento y otorgamiento de un derecho prestacional solicitado como DDHH, debe ponderarse bajo ciertos cánones o parámetros, para que no abata los derechos fundamentales de la población, que ha cubierto los requisitos sustantivos y adjetivos para recibir esa prerrogativa.

En diversas ocasiones, la autoridad ha reconocido y cumplido un derecho prestacional como un Derecho Humano de forma gratuita. Esto permite que otra persona pueda exigir ese mismo servicio, y que ha visto la oportunidad para usufructuar ese bien o servicio público. Uno de los problemas que sucede, es que no se ponderan las situaciones especiales del caso, y que tal vez el recurrente no requiera de asistencia por parte del Estado.

El test propuesto es un mecanismo que enfoca y localiza judicialmente a los $\mathrm{DDHH}$, para que no se acumulen en una caja de Pandora; sino que, que su otorgamiento sea con base en la ponderación del operador jurídico, estimando que no toda exigencia fundamentada en DDHH debe ser resuelta o desahogada incondicionalmente a favor del solicitante, por lo que debe revisar cada asunto, tutelando y protegiendo tanto los DDHH, como los derechos fundamentales de la población.

\section{REFERENCIAS}

ACKERMAN, Bruce. Social Justice in the Liberal State. New Haven: Yale University Press, 1980.

ACKERMAN, Bruce. We the people. Foundations. Cambridge: Harvard University Press, 1991.

ALEXY, Robert. La construcción de los derechos fundamentales. Buenos Aires: Ad hoc, 2010.

ALEXY, Robert. Teoría de los derechos fundamentales. Madrid: Centro de estudios constitucionales, 2007.

ARANGO, Rodolfo. Jurisprudencia constitucional sobre el derecho mínimo vital. Bogotá: Universidad de los Andes, 2002.

BARNETT, Randy. Restoring the lost constitution. Princeton: Princeton University Press, 2004.

BICKEL, Alexander M. The least dangerous power. New Haven: Yale University Press, 1986.

BIX, Brian. Jurisprudence. Durham: Carolina Academic Press, 2004.

CARBONELL, Miguel. Corte, jueces y política. Ciudad de México: Fontamara, 2007.

CARMONA CUENCA, Encarna. Los derechos sociales de prestación y el derecho a un mínimo vital. Anuario multidisciplinar para la modernización de las administraciones públicas, Sevilla, $\mathrm{n}$. 2, p. 173-197, 2006.

CERVANTES, Magdalena. ¿Hay justicia para los DESC? Ciudad de México: UNAM, 2014. 
COSSíO DÍAZ, José Ramón. Problemas de la Justicia Constitucional. In: OROZCO HENRÍQUEZ, J. Jesús (Coord.). Sistemas de Justicia electoral: Evaluación y perspectivas. Ciudad de México: IFE, 1999.

DWORKIN, Ronald. Los derechos en serio. Barcelona: Ariel, 1995.

ELSTER, Jon. Explaining social behavior. Cambridge: Cambridge, 2007.

GÓMEZ SANCHÉZ, Yolanda. Estado Constitucional y protección internacional. In: GÓMEZ SANCHÉZ, Yolanda; PÉREZ MARCOS, Regina María (Coord.). Presente, pasado y futuro de los DDHH. Ciudad de México: CNDH, 2014.

HART, H.L.A. The concept of law. Oxford: Clarendon, 1988.

KOJÉVE, Alexandre. La noción de autoridad. Buenos Aires: Nueva visión, 2005.

LARA SÁENZ, Leoncio. Derechos Humanos y Justicia Electoral. Ciudad de México: Tribunal Electoral del Poder Judicial de la Federación, 2003.

LINZ, Juan J. Problems of democratic transition and consolidation. Baltimore: The Johns Hopkins University, 1996.

MARTÍNEZ PORCAYO, José Fernando Ojesto. Poder, derecho y jueces: la jurisdicción como participación política. In: TRIBUNAL ELECTORAL DEL PODER JUDICIAL DE LA FEDERACIÓN (Org.). Testimonios sobre el desempeño del TEPJF. Ciudad de México: Tribunal Electoral del Poder Judicial de la Federación, 2003.

MEDELLÍN, Ximena. Principio Pro persona. Ciudad de México: Suprema Corte de Justicia de la Nación, 2013.

NINO, Carlos S. El principio de autonomía de la persona. In: NINO, Carlos S. Ética y Derechos Humanos. Buenos Aires: Astrea, 1989.

NINO, Carlos S. The Constitution of deliberative democracy. New Haven: Yale, 1996.

PICARD DE ORSINI, Marie; USECHE, Judith. Una nueva dimensión del Estado de Derecho: el Estado Social de Derecho. Provincia, Mérida, número especial, p. 189-218, 2006.

QUESADA, Jimena. Europa social y democrática de derecho. Madrid: Dykinson, 1997.

RAWLS, John. A theory of justice. Cambridge: Harvard University Press, 1971.

SALAZAR, Pedro. Justicia constitucional y democracia. In: VÁZQUEZ, Rodolfo (Coord.). Corte, jueves y política. Ciudad de México: Fontamara, 2007.

SARLET, Ingo Wolfgang. Mínimo existencial y justicia constitucional. Recurso electrónico consultado: <https://archivos.juridicas.unam.mx/www/bjv/libros/8/3977/29.pdf>. Acceso en: 3 sept. 2018. 
SERPE, Alessandro. Argumentando a partir de los derechos humanos. Revista Utopía y Praxis Latinoamericana, Maracaibo, v. 15, n. 51, 2010.

SILVA HENAO, Juan Fernando. Evolución y origen del concepto de 'Estado Social' incorporado en la Constitución Política colombiana de 1991. Ratio Juris, vol. 7, número 14, ene./jun. 2012.

SPENCER, S. El individuo contra el Estado. Barcelona: Orbis, 1984.

SUPREMA CORTE DE JUSTICIA DE LA NACIÓN. Dignidad humana. Ciudad de México: PJF, 2013. SUPREMA CORTE DE JUSTICIA DE LA NACIÓN. Los derechos humanos y su protección por el PJF. Ciudad de México: Suprema Corte de Justicia de la Nación, 2011.

VANOSSI, Jorge Reinaldo. El Estado de derecho en el constitucionalismo social. Buenos Aires: EUDEBA, 1987.

VILLAR BORDA, Luis. Estado de derecho y Estado social de derecho. Revista Derecho del Estado, n. 20, dic. 2007.

WADE, H. W. Estudio del derecho administrativo. Madrid: Instituto de Estudios Políticos, 1971. WALDRON, Jeremy. Law and disagreement. Mississippi: Oxford University Press, 2004.

WILLIAMS, Melissa; WALDRON, Jeremy. Toleration and its limits. New York: New York University Press, 2008. 